\title{
Neuroradiologic manifestations of COVID-19: what the emergency radiologist needs to know
}

\author{
Michael F. Goldberg ${ }^{1}$ (D) Morton F. Goldberg ${ }^{2}$
}

Received: 16 June 2020 / Accepted: 10 August 2020 / Published online: 21 August 2020

(C) American Society of Emergency Radiology 2020

\begin{abstract}
Coronavirus disease 2019 (COVID-19), caused by severe acute respiratory syndrome coronavirus-2 (SARS-CoV-2), is a global pandemic with a wide spectrum of clinical signs and symptoms. Neurologic manifestations are relatively common, with severe cases often demonstrating striking findings on neuroimaging. Because the neuroradiologic findings may be the first evidence of COVID-19, the emergency radiologist has a critical role to play in not only the detection and management of the disease but also in the safety of other patients and hospital staff. Therefore, radiologists, especially those who specialize in emergency radiology, need to be aware of the neuroradiologic manifestations of COVID-19.
\end{abstract}

Keywords COVID-19 $\cdot$ Encephalopathy $\cdot$ PRES $\cdot$ SARS-CoV-2 $\cdot$ Stroke

\section{Introduction}

Coronavirus disease 2019 (COVID-19), caused by severe acute respiratory syndrome coronavirus-2 (SARS-CoV-2), is a global pandemic that began in December 2019 in Wuhan, China [1]. Since the initial outbreak, COVID-19 has spread rapidly across over 200 countries, resulting in over 18 million confirmed cases and over 700,000 deaths [2]. In the USA, there have been cases reported in all 50 states, resulting in over 4.7 million confirmed cases and over 150,000 deaths [2]. Although typical symptoms are mild, including fever, cough, dyspnea, diarrhea, and myalgies, severe disease often results in pneumonia and subsequent acute respiratory distress syndrome (ARDS) [3].

Pulmonary disease is the most common source of morbidity and mortality in severely affected COVID-19 patients, but there is a substantial body of literature indicating that a variety of neurologic manifestations also characterize this disease. In a study of 214 COVID-19 patients in Wuhan, China, for example, $36 \%$ had neurologic manifestations [4]. These

Michael F. Goldberg

michael.goldberg@ahn.org

1 Division of Neuroradiology, Imaging Institute, Allegheny Health Network, Pittsburgh, PA, USA

2 Department of Ophthalmology, Johns Hopkins Medical Institutions, Baltimore, MD, USA neurologic manifestations were more common in severely affected patients, tended to occur early in the disease course, and could be the initial, presenting clinical evidence of COVID-19 [4]. There are a variety of reported neurologic signs and symptoms of COVID-19, ranging from mild to severe. These include, most commonly, dizziness, headache, delirium, and impaired consciousness $[4,5]$.

Because the neuroradiologic findings may be the first evidence of COVID-19, the emergency radiologist has a critical role to play in not only the detection and management of the disease but also in the safety of other patients and hospital staff. Therefore, radiologists, especially those who specialize in emergency radiology, need to be aware of the neuroradiologic manifestations of COVID-19.

This review article will focus on these neurologic manifestations (with neuroradiologic correlates), which tend to present with more severe signs and symptoms. We have categorized these neurologic manifestations by presumed pathophysiologic processes, especially cerebrovascular disease and inflammatory disease. It should be noted, however, that COVID-19 is a new disease, and all research that is currently available is inherently limited in size, scope, and duration. Therefore, at this point, definitive understanding of disease mechanisms and causal relationships are limited. Furthermore, the underlying pathophysiologic processes may be concurrent and related, rather than distinct and independent; for example, a marked inflammatory response may be the cause of the observed cerebrovascular disease. 
Notably, there are almost certainly neurologic manifestations of COVID-19 without imaging correlates, including mild symptoms, such as headache and dizziness. Even severe neurologic problems associated with COVID-19, including encephalopathy, may show no acute abnormality on brain imaging [6]. Longer term studies are needed to determine if there will be chronic neuroradiologic sequelae.

\section{Cerebrovascular disease}

A study of 214 patients from Wuhan, China, reported an incidence of stroke in $5.7 \%$ of severely affected COVID-19 patients [4]. More recently, in a study of 108 hospitalized COVID-19 patients who underwent neuroimaging, $31 \%$ demonstrated acute ischemia [7]. In a retrospective study of 73 COVID-19 patients with neurologic symptoms, $23 \%$ had ischemic lesions [8]. A report from a large medical system in New York City reported a $0.9 \%$ incidence of acute ischemic stroke (AIS) in 3556 hospitalized COVID-19 patients in the spring of 2020 [9]. Notably, in the New York study, the patients' stroke (not respiratory) symptoms were the reason for admission in $44 \%$ of the stroke cases [9]. The authors of the New York study noted that because severely affected COVID19 patients are often intubated and sedated, the presence of stroke can be overlooked, and therefore, its reported incidence could be spuriously low. In another case series of 64 patients with severe COVID-19, 3 out of 13 patients who underwent brain MRIs demonstrated evidence of ischemic stroke [10]. In another case series from New York, five patients with COVID-19, all under the age of 50 years, presented with large vessel AIS over a 2-week period; this represented an almost 7fold increase in frequency of large vessel stroke seen in previous patients in this age group [11].

Based on the reported cases in the medical literature, strokes that occur in COVID-19 tend to be severe, with high NIH stroke scale (NIHSS) scores [11-13]. Yaghi et al. reported a mortality of 64\% in COVID-19 stroke patients, with the majority of survivors having a clinical outcome of "critically ill." The case series by Oxley et al. with five stroke patients had no deaths, perhaps related to the younger age of this cohort [11].

Typical imaging findings of AIS on non-contrast CT of the head (NCCT) have been reported in the setting of COVID-19 [12]. These findings are similar to those in non-COVID-19 patients, including abnormal hypoattenuation of the brain parenchyma, loss of gray-white differentiation, and sulcal effacement (Fig. 1). Intracranial angiographic imaging in some of these patients has revealed extensive vascular occlusive disease, including large vessel occlusions (LVO) [11, 12]. Markedly reduced flow has been demonstrated on CT angiography, even in the absence of LVO (Fig. 1) [12]. Based on limited case reports, there is a suggestion that thrombosis of the extracranial carotid arteries may play a causative role for stroke in some COVID-19 patients [12, 14, 15].

How does one explain this apparent association between AIS and COVID-19? Although larger scale studies are needed, there is strong evidence that infection with COVID-19, especially in severe disease, leads to a hypercoagulable, prothrombotic state. D-dimer, a product of fibrin clot degradation and an indicator of recent or current clot formation, has been studied in COVID-19 patients. Specifically, D-dimer levels of $>1 \mu \mathrm{g} / \mathrm{mL}$ (normal $<0.5 \mu \mathrm{g} / \mathrm{mL}$ ) were found to be associated with an 18-fold increase in death in a study of 191 hospitalized patients with COVID-19 [3]. Other studies have also confirmed increased D-dimer levels in COVID-19 patients; higher values were disproportionately seen in severe cases [16-18]. Moreover, in a study of 183 patients with COVID-19, Tang et al. found that D-dimer levels were significantly higher in non-survivors compared with survivors [19]. This evidence of a prothrombotic state correlates positively with the observed increase in complications of hypercoagulability, including pulmonary embolism and deep vein thrombosis $[3,10,20]$.

Another potential mechanism of AIS and COVID-19 involves the antiphospholipid syndrome (APS), an autoimmune disorder resulting in recurrent arterial and venous thromboses. In a case series of 3 patients with severe COVID-19, each of whom had multiple cerebral infarcts, researchers identified the APS as likely contributing to the coagulopathy seen in these patients [21].

Damage, inflammation, and/or dysfunction of the endothelium, the layer of cells lining blood vessels, are also likely to be responsible for the development of thrombotic events observed in COVID-19, including cerebral ischemia [22, 23]. Angiotensin-converting enzyme 2 (ACE2) receptors are the host cell receptors for SARS-Cov-2 [24]. ACE2 receptors are present in a variety of organs, including the lung and heart. Notably, ACE2 is also expressed by vascular endothelium, and the virus is known to infect cells via binding of its spike protein to the ACE2 receptors [25]. Varga et al. showed that infection with SARS-CoV-2 resulted in not only direct viral infection of the endothelium but also endothelial inflammation and endothelial cell death [23]. These events result in greater vasoconstriction and the development of a prothrombotic state [23].

In addition, large vessel strokes were also reported in the 2004 SARS epidemic; SARS was due to an outbreak of the virus, SARS-CoV-1, a member of the same Betacoronavirus genus as SARS-CoV-2 [26].

Another cerebrovascular manifestation of COVID-19 may be the development of cerebral venous thrombosis (CVT), which has been widely reported as a complication of COVID-19-associated coagulopathy, resulting in multisystem organ failure [19, 22, 27]. Specifically, several researchers have raised the possibility of an association between cerebral 


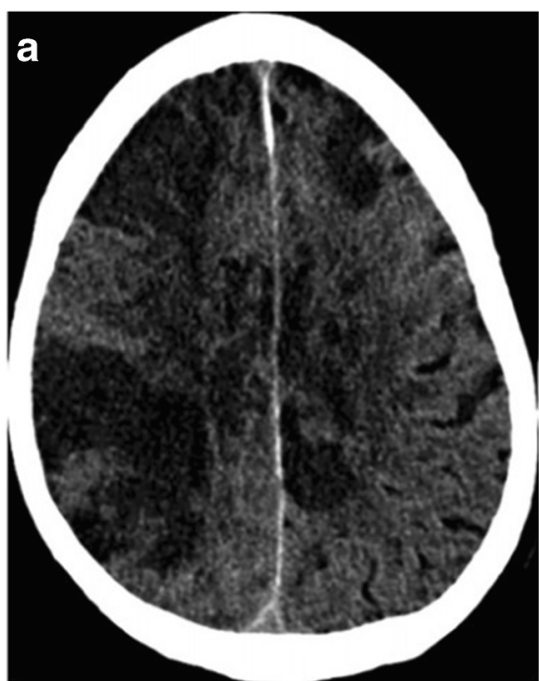

Fig. 1 a NCCT of the head in a COVID-19 patient demonstrates findings of AIS, including hypoattenuation of the brain parenchyma, loss of graywhite differentiation, and sulcal effacement. b Axial CTA of the head in the same patient demonstrates reduced vascular filling in branches of the right middle cerebral artery (arrowheads) and bilateral anterior cerebral

venous thrombosis and COVID-19 [28-32]. Once again, this potential association is based on a small number of patients, so a definitive, causal relationship has yet to be established, although it is suspected. Based on a case series of three patients, another case series of two patients, and three individual case reports, several apparently common features of CVT in COVID-19 have been observed [28-32]. All eight patients in these studies presented with neurologic complaints, ranging from mild to severe, including headache, confusion, aphasia, altered mental status, seizure, and hemiparesis. In all cases, respiratory symptoms were initially mild or non-existent, despite abnormal findings on chest imaging in seven out of eight patients that were consistent with COVID-19. In all eight patients, NCCT revealed edema and hemorrhage, consistent with cerebral hemorrhagic venous infarction; in two of those cases, hyperdensity was identified within intracranial veins, representing intravascular thrombosis (Fig. 2).

On venography, thromboses were seen in the dural venous sinuses, deep cerebral veins, and cortical veins. Notably, the internal cerebral veins are thrombosed in four out of eight cases (Fig. 3). In one case, the researchers speculated that the source of hemorrhagic venous infarct was thrombotic microangiopathy due to compromised flow in deep medullary veins [28]. In the 6 cases in which mortality was reported, the death rate was $67 \%$. This high mortality rate is in contradistinction to a reported CVT mortality rate of $4-8 \%$ in nonCOVID-19 cases. The higher mortality rate seen in these COVID-19 patients may be related to the involvement of the deep venous system and/or non-neurologic complications of COVID-19 [33, 34]. The predilection for thrombosis of the deep venous system is also striking-in a large, international, prospective multicenter study of CVT in non-COVID-19

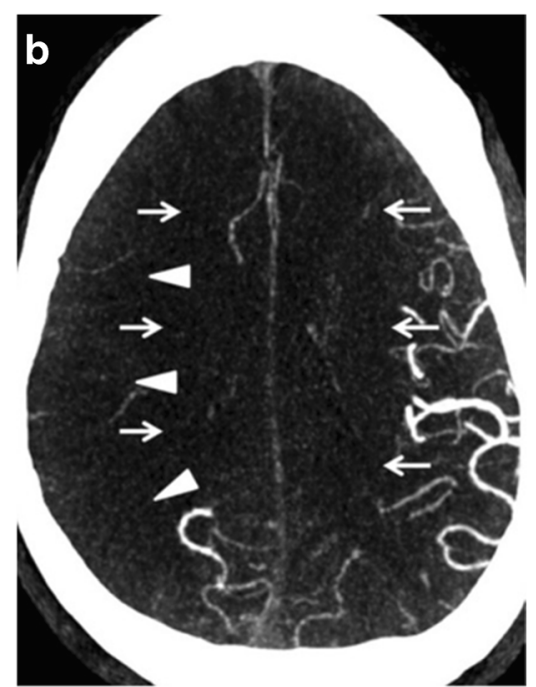

arteries (arrows). Reference: Goldberg MF, Goldberg MF, Cerejo R, Tayal A. Cerebrovascular Disease in COVID-19. American Journal of Neuroradiology. 2020. doi:https://doi.org/10.3174/ajnr.a6588. (Permission granted)

patients, thrombosis of the deep venous system occurred in only $10.9 \%$ of cases [34].

There has been a single case report of an acute, severe intracranial hemorrhage due to a ruptured pericallosal aneurysm in a patient with COVID-19 [35]. The authors of this report acknowledge that it is impossible to know whether concomitant COVID-19 infection caused the formation and/or rupture of the aneurysm. However, they propose that systemic inflammation could have led to instability of the wall of the aneurysm.

\section{Thrombotic microangiopathy}

Nicholson et al. published a case series of four critically ill COVID-19 patients, three of whom were on extracorporeal membrane oxygenation (ECMO) [36]. These four patients underwent neuroimaging due to changes in neurologic status. In these patients, brain imaging demonstrates several different types of hemorrhages, including parenchymal hemorrhage, diffuse petechial hemorrhage, and subarachnoid hemorrhage (Fig. 4). Although the authors acknowledge the inherent limitations of a small case series in drawing causal relationships, they refer to the extensive, early literature of hypercoagulability and endothelial dysfunction associated with COVID-19. Therefore, they hypothesize that the intracranial hemorrhage seen in their case series could be due to a diffuse thrombotic microangiopathy with both arterial and venous involvement. Although other studies have demonstrated definitive, pathologic evidence of microthrombi and endothelial dysfunction in other organ systems, this study did not include any pathologic/autopsy analyses $[22,37]$. Lastly, the authors note that ECMO alone (in the absence of SARS-CoV-2 infection) is a risk factor for intracranial 

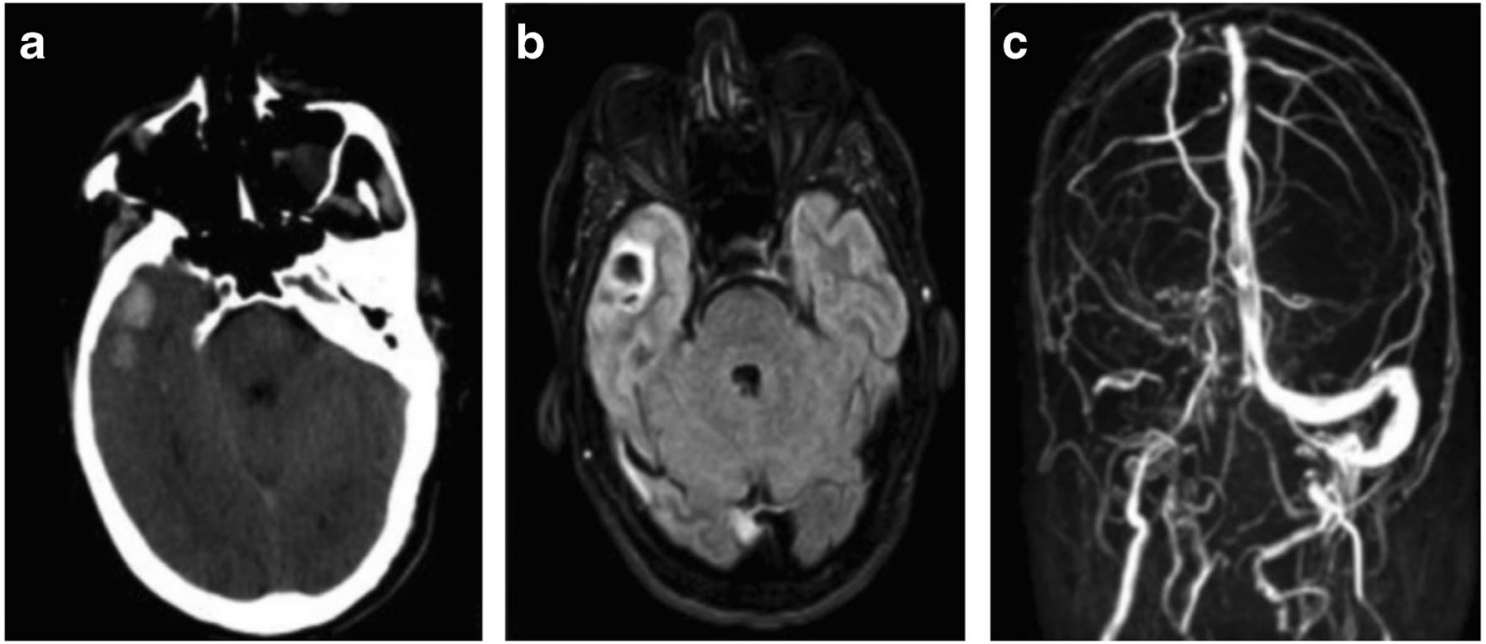

Fig. 2 a NCCT of the head in a COVID-19 patient shows hemorrhage in the anterior right temporal lobe. b Axial FLAIR image from brain MRI in the same patient shows hemorrhage and edema, most consistent with hemorrhagic venous infarct. c Intracranial MR venography in the same patient demonstrates absence of flow-related enhancement in the right

hemorrhage, further limiting the generalizability of this small case series. Notably, however, in a case series of nine patients with COVID-19 (none of whom were on ECMO), Fitsiori et al. described cerebral microbleeds in unusual distributions, including involvement of the internal capsule, corpus callosum, and middle cerebellar peduncles [38].

In two recent retrospective, observational studies of COVID19 patients who underwent brain MRI, intracranial microhemorrhages were identified with a frequency of $28 \%$ and 5\% in articles by Chougar et al. and Kremer et al., respectively $[8,39]$.

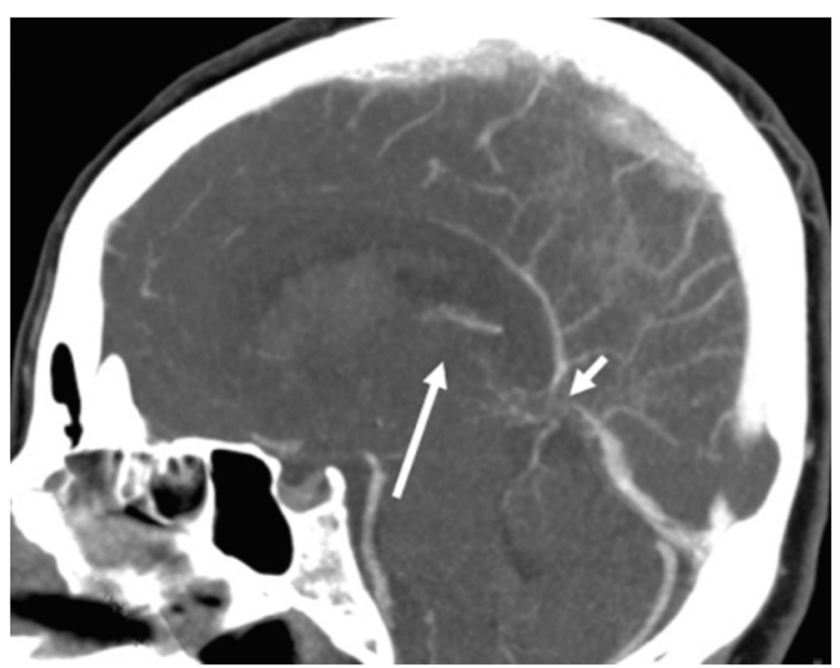

Fig. 3 Sagittal reconstruction of an intracranial CT venogram in a patient with COVID-19 shows filling defects in the vein of Galen (short arrow) and internal cerebral veins (long arrow), consistent with thromboses of the deep cerebral venous system. Reference: Cavalcanti DD, Raz E, Shapiro M, et al. Cerebral Venous Thrombosis associated with COVID-19. American Journal of Neuroradiology. 2020;41(8). doi:https://doi.org/10.3174/ajnr.a6644. (Permission granted)

transverse and sigmoid sinuses, consistent with dural venous sinus thromboses. Reference: Hemasian H, Ansari B. First case of Covid-19 presented with cerebral venous thrombosis: A rare and dreaded case. Revue Neurologique. 2020. doi:https://doi.org/10.1016/j.neurol.2020.04.013. (Permission granted)

\section{Infectious and inflammatory disease}

The delayed onset of manifestations of severe COVID-19 raises the possibility of a maladaptive host response to infection [40]. Specifically, the cytokine storm syndrome has been raised as a possible culprit in the morbidity and mortality of COVID-19 [41]. This hyperinflammatory response can result in fever, cytopenias, coagulopathy, ARDS, multiorgan failure, and death [41]. This syndrome could explain, in part, the hypercoagulability, endothelial dysfunction, and breakdown of the blood-brain barrier (BBB) that are thought to occur in severe COVID-19. In turn, these events could explain some of the neurologic sequelae (and their neuroimaging correlates) observed in severe COVID19. Furthermore, the breakdown of the BBB might allow direct entry of the SARS-CoV-2 into the brain [42].

The neuroinvasive potential of SARS-CoV-2 is an important consideration when attempting to understand the underlying mechanisms of the myriad neurologic complications that appear to be associated with COVID-19. SARS-CoV-2, along with severe acute respiratory syndrome-CoV-1 (SARS) and Middle East respiratory syndrome (MERS), is a member of the Betacoronavirus genus, whose species are thought to be neuroinvasive [43, 44]. Both SARS and MERS have been associated with neurological symptoms. For example, a study of 23 MERS patients at one hospital showed that almost $20 \%$ of patients had neurological complications, including encephalitis, Guillain-Barre syndrome, weakness, and neuropathy [45]. Both SARS and MERS have shown neurotropic features, including the ability to infect neuronal and glial cells [46-48]. But, how would a respiratory virus, like SARS-CoV2 , get access to the central nervous system (CNS)? The two most likely theories of accessing the CNS include hematogenous spread and neuronal retrograde spread $[44,46]$. 


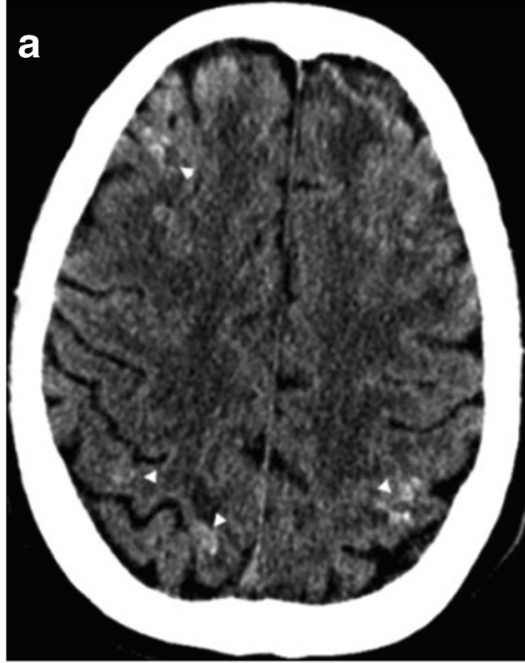

Fig. 4 a. NCCT of the head in a COVID-19 patient demonstrates numerous punctate foci of hyperdensity (arrowheads), consistent with petechial hemorrhage. b Axial susceptibility-weighted image (SWI) from a brain MRI of the same patient demonstrates extensive foci of hypointensity, consistent with susceptibility artifact from hemorrhage. Findings were

In the theory of hematogenous spread, the body's intense inflammatory response may disrupt the BBB, and/or the virus may directly infect endothelial cells, thereby accessing the CNS. In the theory of neuronal retrograde spread, the airborne viral particles access the brain via peripheral nerve endings of cranial nerves, possibly including the olfactory nerve and trigeminal nerve $[46,47]$. In support of the theory of neuronal retrograde spread, a recent case report of a COVID-19 patient with anosmia demonstrated abnormal signal in the olfactory bulbs [49]. Regardless, prior studies that evaluated neuroimaging findings of patients infected with other members of the Betacoronavirus genus have also demonstrated significant abnormalities, including intracranial hemorrhage and evidence of acute disseminated encephalomyelitis (ADEM), which could represent sequelae of inflammatory response and/or direct CNS infection [50,51].

\section{Acute hemorrhagic necrotizing encephalopathy}

Poyiadji et al. published a case report of a COVID-19 patient presenting with cough, fever, and altered mental status [52]. NCCT revealed hypoattenuation in the bilateral thalami. Brain MRI showed enhancing hemorrhagic lesions bilaterally within the medial temporal lobes, subinsular regions, and thalami (Fig. 5). Based on these findings, the diagnosis was COVID19-related acute hemorrhagic encephalopathy. The authors based their diagnosis on not only the above-described imaging features but also on the known association between acute necrotizing encephalopathy (ANE) and other viral infections, including influenza [52]. As mentioned above, cytokine storm

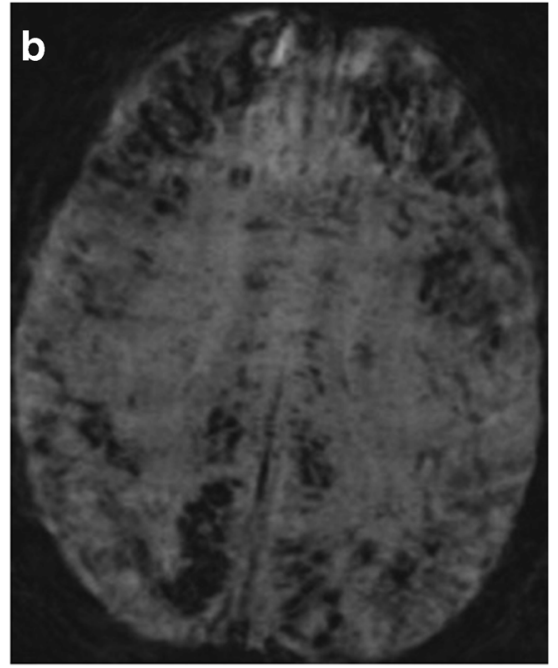

consistent with thrombotic microangiopathy. Reference: Nicholson P, Alshafai L, Krings T. Neuroimaging Findings in Patients with COVID19. American Journal of Neuroradiology. 2020;41(8). doi:https://doi.org/ 10.3174/ajnr.a6630. (Permission granted)

syndrome has been strongly associated with COVID-19 and other severe infections, and this may be the likely underlying etiology for ANE, with resultant breakdown in the BBB [41].

\section{Hemorrhagic posterior reversible encephalopathy syndrome}

Hemorrhagic posterior reversible encephalopathy syndrome (PRES) has recently been described in the setting of COVID-19 [42]. In a small case series, Franceschi et al. detailed similar imaging findings in two patients with COVID19 who underwent neuroimaging after the development of altered mental status. In a 48-year-old male, a NCCT demonstrates subcortical edema in the bilateral parieto-occipital regions with a small component of hemorrhage (Fig. 6). The NCCT on the second patient, a 67-year-old female, also demonstrated edema in the bilateral parieto-occipital regions. A follow-up brain MRI showed more extensive edema, including not only the bilateral parieto-occipital regions but also the right frontal lobe, basal ganglia, and cerebellar hemispheres. Hemorrhage was also seen in the right parieto-occipital region. No evidence of arterial or venous thromboses was identified in either patient. Imaging findings were considered to be consistent with PRES complicated by hemorrhage [53].

One case of non-hemorrhagic PRES in a COVID-19 patient has been reported in a case series of hospitalized patients in Italy, and two cases have been reported in a retrospective study from France [7, 8].

The precise pathophysiology of PRES remains unknown, and assessing the potential relationship between COVID-19 and PRES on the basis of a small case series is challenging. 

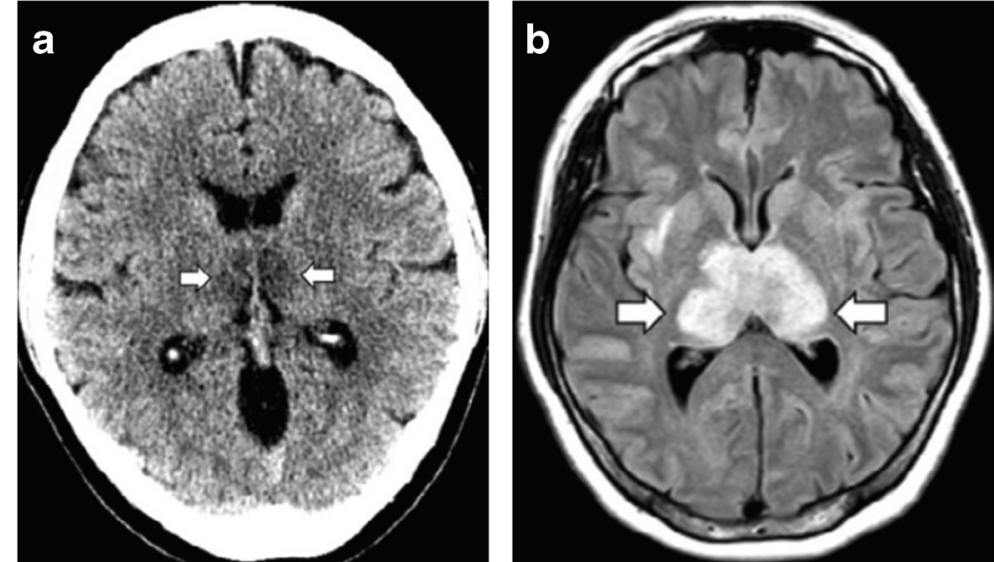

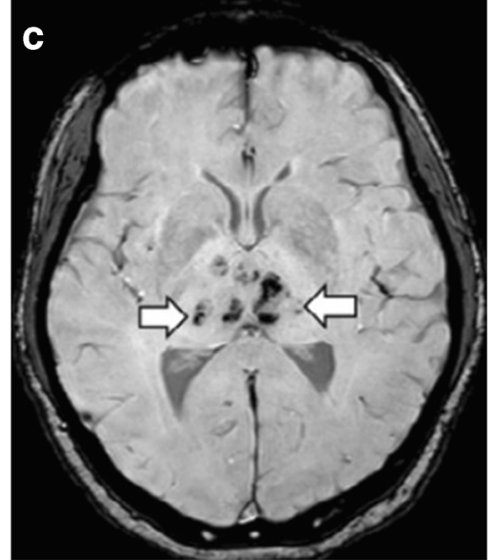

Fig. 5 a NCCT of the head in a COVID-19 patient shows symmetric edema within the bilateral thalami (arrows). b Axial FLAIR image from brain MRI in the same patient shows edema and mass effect in the bilateral thalami (arrows). c Axial SWI from a brain MRI of the same patient demonstrates susceptibility artifact, confirming the presence of hemorrhage (arrows). The bilateral medial temporal lobes also demonstrated

However, Franceschi et al. propose several potential mechanisms for PRES in the setting of COVID-19, including breakdown of the BBB, either indirectly due to cytokine storm syndrome and/or directly via endothelial dysfunction from binding of the SARS-CoV2 to endothelial-expressed ACE2 receptors. Notably, the two patients in their case series had labile blood pressure, and the authors acknowledge that the

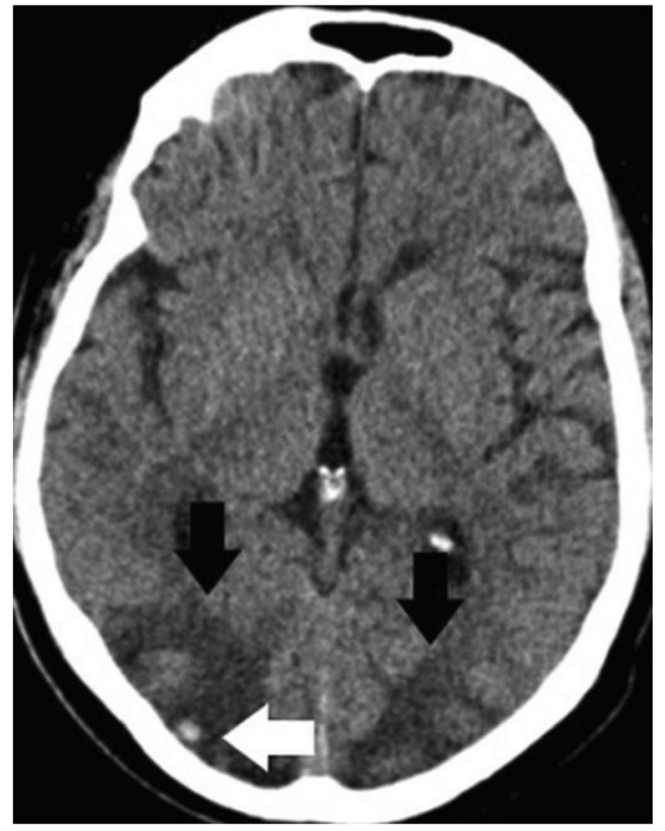

Fig. 6 NCCT of the head in a COVID-19 patient demonstrates edema in the bilateral occipital lobes, consistent with PRES. Within the edema of the right occipital lobe, there is a small, superimposed parenchymal hemorrhage (arrow). Reference: Franceschi A, Ahmed O, Giliberto L, Castillo M. Hemorrhagic Posterior Reversible Encephalopathy Syndrome as a Manifestation of COVID-19 Infection. American Journal of Neuroradiology. 2020. doi:https://doi.org/10.3174/ajnr. a6595. (Permission granted) edema and hemorrhage (not shown), and findings were consistent with acute hemorrhagic necrotizing encephalopathy. Reference: Poyiadji N, Shahin G, Noujaim D, Stone M, Patel S, Griffith B. COVID-19-associated Acute Hemorrhagic Necrotizing Encephalopathy: CT and MRI Features. Radiology. 2020:201187. doi:https://doi.org/10.1148/radiol. 2020201187. (Permission granted)

PRES identified in both patients may have been due to this elevated blood pressure, a well-known risk factor for PRES.

\section{White matter disease}

\section{Diffuse Leukoencephalopathy}

In two recent retrospective studies, 2-6\% of COVID-19 patients who underwent brain MRI demonstrated multifocal and/or confluent white matter lesions [8, 39].

In another case series of COVID-19 patients who underwent brain MRI for depressed mental status, over 33\% demonstrated diffuse, confluent, and symmetric T2 hyperintensities and restricted diffusion of the bilateral deep and subcortical white matter [54]. Findings were consistent with diffuse leukoencephalopathy. Notably, all of the patients with these findings were critically ill and had been on mechanical ventilation for an average of 26.5 days. Based on the imaging characteristics and late onset, the authors hypothesized that the etiology of the diffuse leukoencephalopathy was delayed post-hypoxic insult with subsequent demyelination. So, in this case, the neurologic sequelae and associating neuroimaging findings likely represent an indirect, rather than direct, inflammatory response to COVID-19.

\section{Acute disseminated encephalomyelitis and other demyelinating diseases}

As mentioned above, ADEM has been reported in the past in a patient infected with coronavirus OC43, which, like SARSCoV2, is a member of the Betacoronavirus genus [51]. ADEM is a demyelinating disease that affects the CNS, 
usually in the pediatric and young adult population. Notably, it often occurs after a viral illness, commonly including a respiratory infection. Clinical signs and symptoms are variable but can include encephalopathy, seizure, weakness, and visual changes.

Since the outbreak of COVID-19, there have been two case reports of patients with presumptive ADEM due to COVID$19[55,56]$. In each case, the COVID-19 patient presented with acute, multifocal neurological changes. The brain MRIs performed on each patient demonstrated lesions in the periventricular, deep, and juxtacortical white matter, which showed variable enhancement. In one case, lesions were also identified in the cervical and thoracic spinal cord [55]. Although the findings in each of these cases were non-specific, the authors felt that other etiologies, including other demyelinating diseases, were unlikely, especially given the clinical history of COVID-19.

In a case report by Zanin et al., a COVID-19 adult patient with seizures underwent brain MRI, which demonstrated nonenhancing lesions of the periventricular white matter; spine MRI revealed lesions of the cervical and thoracic spinal cord [57]. As this patient had a history of normal brain MRIs and had complained of recent anosmia and dysgeusia, the authors felt that a demyelinating process had been initiated due to an immune-mediated response to SARS-CoV-2 infection. The authors did not mention ADEM in their article as a possible diagnosis.

Multiple sclerosis, as a result of an immune response to SARS-CoV-2 infection, has also been described in one case report [58]. In this report, Palao et al. describe a 29-year-old female presenting with decrease in visual acuity in the right eye and an orbital MRI consistent with right-sided optic neuritis. The MRI of the brain also demonstrated demyelinating lesions of the periventricular white matter with variable enhancement. Although the patient's SARS-CoV-2 PCR analysis from nasopharyngeal swab was negative, the authors assumed that she had had a recent infection due to (1) positive IgM and $\mathrm{IgG}$ on immunological testing, (2) complaints of anosmia and dysgeusia 2-3 weeks prior to her visual complaints, and (3) the patient's cohabitation with a person with confirmed SARS-CoV-2 infection. The authors suggest that the patient's multiple sclerosis likely predated her infection, but that the body's immune response to SARS-CoV-2 could have acted as an exacerbating factor in triggering her initial presentation of her previously undiagnosed multiple sclerosis.

\section{Conclusion}

Although initially considered a respiratory disease, COVID19 actually affects a wide range of organ systems, including the CNS. Importantly, the neurologic manifestations are relatively common, and their neuroradiologic correlates may be the first signs of infection. Radiologists, especially those who practice in the emergency setting, therefore play a critical role in evaluating COVID-19 patients and protecting other patients and hospital staff.

\section{Compliance with ethical standards}

Conflict of interest The authors declare that they have no conflict of interest.

\section{References}

1. Phelan AL, Katz R, Gostin LO (2020) The novel coronavirus originating in Wuhan, China. Jama 323(8):709. https://doi.org/10.1001/ jama.2020.1097

2. Johns Hopkins University Coronavirus Resource Center. https:// coronavirus.jhu.edu/. Accessed on 5 Aug 2020

3. Zhou F, Yu T, Du R et al (2020) Clinical course and risk factors for mortality of adult inpatients with COVID-19 in Wuhan, China: a retrospective cohort study. Lancet 395(10229):1054-1062. https:// doi.org/10.1016/s0140-6736(20)30566-3

4. Mao L, Jin H, Wang M, Hu Y, Chen S, He Q, Chang J, Hong C, Zhou Y, Wang D, Miao X, Li Y, Hu B (2020) Neurologic manifestations of hospitalized patients with coronavirus disease 2019 in Wuhan, China. JAMA Neurol 77:683. https://doi.org/10.1001/ jamaneurol.2020.1127

5. Kotfis K, Roberson SW, Wilson JE, Dabrowski W, Pun BT, Ely EW (2020) COVID-19: ICU delirium management during SARSCoV-2 pandemic. Crit Care 24(1). https://doi.org/10.1186/s13054020-02882-x

6. Filatov A, Sharma P, Hindi F, Espinosa PS (2020) Neurological complications of coronavirus disease (COVID-19): encephalopathy. Cureus. https://doi.org/10.7759/cureus.7352

7. Mahammedi A, Saba L, Vagal A, Leali M, Rossi A, Gaskill M, Sengupta S, Zhang B, Carriero A, Bachir S, Crivelli P, Paschè A, Premi E, Padovani A, Gasparotti R (2020) Imaging in neurological disease of hospitalized COVID-19 patients: an Italian multicenter retrospective observational study. Radiology. 201933:201933. https://doi.org/10.1148/radiol.2020201933

8. Chougar L, Shor N, Weiss N, Galanaud D, Leclercq D, Mathon B, Belkacem S, Stroër S, Burrel S, Boutolleau D, Demoule A, Rosso C, Delorme C, Seilhean D, Dormont D, Morawiec E, Raux M, Demeret S, Gerber S, Trunet S, Similowski T, Degos V, Rufat P, Corvol JC, Lehéricy S, Pyatigorskaya N, On behalf of the CoCo Neurosciences study group (2020) Retrospective observational study of brain magnetic resonance imaging findings in patients with acute SARS-CoV-2 infection and neurological manifestations. Radiology. 202422:202422. https://doi.org/10.1148/radiol. 2020202422

9. Yaghi S, Ishida K, Torres J et al (2020) SARS2-CoV-2 and stroke in a New York healthcare system. Stroke. https://doi.org/10.1161/ strokeaha. 120.03033

10. Helms J, Kremer S, Merdji H, Clere-Jehl R, Schenck M, Kummerlen C, Collange O, Boulay C, Fafi-Kremer S, Ohana M, Anheim M, Meziani F (2020) Neurologic features in severe SARSCoV-2 infection. N Engl J Med 382:2268-2270. https://doi.org/10. 1056/nejmc2008597

11. Oxley TJ, Mocco J, Majidi S et al (2020) Large-vessel stroke as a presenting feature of Covid-19 in the young. N Engl J Med 382(20). https://doi.org/10.1056/nejmc2009787 
12. Goldberg MF, Goldberg MF, Cerejo R, Tayal A (2020) Cerebrovascular disease in COVID-19. Am J Neuroradiol 41: 1170-1172. https://doi.org/10.3174/ajnr.a6588

13. Yaghi S, Ishida K, Torres J, Mac Grory B, Raz E, Humbert K, Henninger N, Trivedi T, Lillemoe K, Alam S, Sanger M, Kim S, Scher E, Dehkharghani S, Wachs M, Tanweer O, Volpicelli F, Bosworth B, Lord A, Frontera J (2020) SARS2-CoV-2 and stroke in a New York healthcare system. Stroke. 51:2002-2011. https:// doi.org/10.1161/strokeaha.120.030335

14. Singh TM, Lee A, Vo M et al (2020) Urgent carotid endarterectomy in a COVID-19 patient: standard approach with some adjustments. Vasc Dis Manag 17(5):E104-E109

15. Franceschi AM, Arora R, Wilson L et al (2020) Neurovascular complications in COVID-19 infection: case series. Am J Neuroradiol. https://doi.org/10.3174/ajnr.a6655

16. Chen N, Zhou M, Dong X, Qu J, Gong F, Han Y, Qiu Y, Wang J, Liu Y, Wei Y, Xia J', Yu T, Zhang X, Zhang L (2020) Epidemiological and clinical characteristics of 99 cases of 2019 novel coronavirus pneumonia in Wuhan, China: a descriptive study. Lancet 395(10223):507-513. https://doi.org/10.1016/ s0140-6736(20)30211-7

17. Wang D, Hu B, Hu C, Zhu F, Liu X, Zhang J, Wang B, Xiang H, Cheng Z, Xiong Y, Zhao Y, Li Y, Wang X, Peng Z (2020) Clinical characteristics of 138 hospitalized patients with 2019 novel coronavirus-infected pneumonia in Wuhan, China. Jama 323(11): 1061. https://doi.org/10.1001/jama.2020.1585

18. Wan S, Xiang Y, Fang W, Zheng Y, Li B, Hu Y, Lang C, Huang D, Sun Q, Xiong Y, Huang X, Lv J, Luo Y, Shen L, Yang H, Huang G, Yang R (2020) Clinical features and treatment of COVID-19 patients in Northeast Chongqing. J Med Virol 92:797-806. https://doi. org/10.1002/jmv.25783

19. Tang N, Li D, Wang X, Sun Z (2020) Abnormal coagulation parameters are associated with poor prognosis in patients with novel coronavirus pneumonia. J Thromb Haemost 18(4):844-847. https:// doi.org/10.1111/jth.14768

20. Wang W, Sun Q, Bao Y, Liang M, Meng Q, Chen H, Li J, Wang H, Li H, Shi Y, Li Z, Wang X, Zhao S, Wang H, Xiao J, Chen L, Zheng Y, Wang D, Jiao J, Han K (2020) Analysis of risk factors for the thromboembolic events from 88 patients with COVID-19 pneumonia in Wuhan, China: a retrospective report. SSRN Electron J. https://doi.org/10.2139/ssrn.3559633

21. Zhang Y, Xiao M, Zhang S et al (2020) N Engl J Med 382(17). https://doi.org/10.1056/nejmc2007575

22. Ackermann M, Verleden SE, Kuehnel M, Haverich A, Welte T, Laenger F, Vanstapel A, Werlein C, Stark H, Tzankov A, Li WW, Li VW, Mentzer SJ, Jonigk D (2020) Pulmonary vascular endothelialitis, thrombosis, and angiogenesis in Covid-19. N Engl J Med 383:120-128. https://doi.org/10.1056/nejmoa2015432

23. Varga Z, Flammer AJ, Steiger P, Haberecker M, Andermatt R, Zinkernagel AS, Mehra MR, Schuepbach RA, Ruschitzka F, Moch H (2020) Endothelial cell infection and endotheliitis in COVID-19. Lancet 395(10234):1417-1418. https://doi.org/10. 1016/s0140-6736(20)30937-5

24. Hoffmann M, Kleine-Weber H, Schroeder S et al (2020) SARSCoV-2 cell entry depends on ACE2 and TMPRSS2 and is blocked by a clinically proven protease inhibitor. Cell 181(2). https://doi. org/10.1016/j.cell.2020.02.052

25. Clerkin KJ, Fried JA, Raikhelkar J, Sayer G, Griffin JM, Masoumi A, Jain SS, Burkhoff D, Kumaraiah D, Rabbani LR, Schwartz A, Uriel N (2020) COVID-19 and cardiovascular disease. Circulation. 141(20):1648-1655. https://doi.org/10.1161/circulationaha.120. 046941

26. Umapathi T, Kor AC, Venketasubramanian N, Lim CCT, Pang BC, Yeo TT, Lee CC, Lim PL, Ponnudurai K, Chuah KL, Tan PH, Tai DYH, Ang SPB (2004) Large artery ischaemic stroke in severe acute respiratory syndrome (SARS). J Neurol 251(10):12271231. https://doi.org/10.1007/s00415-004-0519-8

27. Xie Y, Wang X, Yang P, Zhang S (2020) COVID-19 Complicated by acute pulmonary embolism. Radiol: Cardiothor Imag 2(2). https://doi.org/10.1148/ryct.2020200067

28. Cavalcanti DD, Raz E, Shapiro M et al (2020) Cerebral venous thrombosis associated with COVID-19. Am J Neuroradiol 41(8). https://doi.org/10.3174/ajnr.a6644

29. Chougar L, Shor N, Mathon B, Degos V, Weiss N (2020) Atypical deep cerebral vein thrombosis with hemorrhagic venous infarction in a COVID-19-positive patient. Am J Neuroradiol 41(8). https:// doi.org/10.3174/ajnr.a6641

30. Hemasian H, Ansari B (2020) First case of Covid-19 presented with cerebral venous thrombosis: a rare and dreaded case. Rev Neurol 176:521-523. https://doi.org/10.1016/j.neurol.2020.04.013

31. Klein DE, Libman R, Kirsch C, Arora R (2020) Cerebral venous thrombosis: atypical presentation of COVID-19 in the young. J Stroke Cerebrovasc Dis 104989:104989. https://doi.org/10.1016/j. jstrokecerebrovasdis.2020.104989

32. Poillon G, Obadia M, Perrin M, Savatovsky J, Lecler A (2020) Cerebral venous thrombosis associated with COVID-19 infection: causality or coincidence? J Neuroradiol. https://doi.org/10.1016/j. neurad.2020.05.003

33. Patrícia C, Ferro JM, Lindgren AG, Bousser M-G, Stam J, Barinagarrementeria $\mathrm{F}$ (2005) Causes and predictors of death in cerebral venous thrombosis. Stroke. 36(8):1720-1725. https://doi. org/10.1161/01.str.0000173152.84438.1c

34. Ferro JM, Patrícia C, Stam J, Bousser M-G, Barinagarrementeria F (2004) Prognosis of cerebral vein and dural sinus thrombosis. Stroke. 35(3):664-670. https://doi.org/10.1161/01.str. 0000117571.76197 .26

35. Muhammad S, Petridis A, Cornelius JF, Hänggi D (2020) Letter to editor: severe brain haemorrhage and concomitant COVID-19 infection: a neurovascular complication of COVID-19. Brain Behav Immun. https://doi.org/10.1016/j.bbi.2020.05.015

36. Nicholson P, Alshafai L, Krings T (2020) Neuroimaging findings in patients with COVID-19. Am J Neuroradiol 41(8). https://doi.org/ 10.3174/ajnr.a6630

37. Magro C, Mulvey JJ, Berlin D, Nuovo G, Salvatore S, Harp J, Baxter-Stoltzfus A, Laurence J (2020) Complement associated microvascular injury and thrombosis in the pathogenesis of severe COVID-19 infection: a report of five cases. Transl Res 220:1-13. https://doi.org/10.1016/j.trs1.2020.04.007

38. Fitsiori A, Pugin D, Thieffry C, Lalive P, Vargas MI (2020) Unusual microbleeds in brain MRI of Covid-19 patients. J Neuroimaging. https://doi.org/10.1111/jon.12755

39. Kremer S, Lersy F, Sèze JD et al (2020) Brain MRI findings in severe COVID-19: a retrospective observational study. Radiology. 2020:202222. https://doi.org/10.1148/radiol.2020202222

40. Berlin DA, Gulick RM, Martinez FJ (2020) Severe Covid-19. N Engl J Med. https://doi.org/10.1056/nejmcp2009575

41. Mehta P, Mcauley DF, Brown M, Sanchez E, Tattersall RS, Manson JJ (2020) COVID-19: consider cytokine storm syndromes and immunosuppression. Lancet 395(10229):1033-1034. https:// doi.org/10.1016/s0140-6736(20)30628-0

42. Franceschi A, Ahmed O, Giliberto L, Castillo M (2020) Hemorrhagic posterior reversible encephalopathy syndrome as a manifestation of COVID-19 infection. Am J Neuroradiol 41: 1173-1176. https://doi.org/10.3174/ajnr.a6595

43. Desforges M, Coupanec AL, Stodola JK, Meessen-Pinard M, Talbot PJ (2014) Human coronaviruses: viral and cellular factors involved in neuroinvasiveness and neuropathogenesis. Virus Res 194:145-158. https://doi.org/10.1016/j.virusres.2014.09.011

44. Calcagno N, Colombo E, Maranzano A, Pasquini J, Keller Sarmiento IJ, Trogu F, Silani V (2020) Rising evidence for 
neurological involvement in COVID-19 pandemic. Neurol Sci 41: 1339-1341. https://doi.org/10.1007/s10072-020-04447-w

45. Kim J-E, Heo J-H, Kim H-O, Song SH, Park SS, Park TH, Ahn JY, Kim MK, Choi JP (2017) Neurological complications during treatment of Middle East respiratory syndrome. J Clin Neurol 13(3): 227-233. https://doi.org/10.3988/jcn.2017.13.3.227

46. Morris M, Zohrabian V (2020) Neuroradiologists, be mindful of the neuroinvasive potential of COVID-19. Am J Neuroradiol 41:E37E39. https://doi.org/10.3174/ajnr.a6551

47. Li YC, Bai WZ, Hashikawa T (2020) The neuroinvasive potential of SARS-CoV2 may play a role in the respiratory failure of COVID-19 patients. J Med Virol 92(6):552-555. https://doi.org/ 10.1002/jmv. 25728

48. Desforges M, Coupanec AL, Dubeau P et al (2019) Human coronaviruses and other respiratory viruses: underestimated opportunistic pathogens of the central nervous system? Viruses. 12(1):14. https://doi.org/10.3390/v12010014

49. Politi LS, Salsano E, Grimaldi M (2020) Magnetic resonance imaging alteration of the brain in a patient with coronavirus disease 2019 (COVID-19) and anosmia. JAMA Neurol 77:1028. https:// doi.org/10.1001/jamaneurol.2020.2125

50. Algahtani H, Subahi A, Shirah B (2016) Neurological complications of Middle East respiratory syndrome coronavirus: a report of two cases and review of the literature. Case Rep Neurol Med 2016: 1-6. https://doi.org/10.1155/2016/3502683

51. Yeh EA, Collins A, Cohen ME, Duffner PK, Faden H (2003) Detection of coronavirus in the central nervous system of a child with acute disseminated encephalomyelitis. Pediatrics 113(1). https://doi.org/10.1542/peds.113.1.e73

52. Poyiadji N, Shahin G, Noujaim D, Stone M, Patel S, Griffith B (2020) COVID-19-associated acute hemorrhagic necrotizing encephalopathy: CT and MRI features. Radiology. 2020:201187. https://doi.org/10.1148/radiol.2020201187

53. Bartynski W (2008) Posterior reversible encephalopathy syndrome, part 1: fundamental imaging and clinical features. Am J Neuroradiol 29(6):1036-1042. https://doi.org/10.3174/ajnr.a0928

54. Radmanesh A, Derman A, Lui YW, Raz E, Loh JP, Hagiwara M, Borja MJ, Zan E, Fatterpekar GM (2020) COVID-19 -associated diffuse leukoencephalopathy and microhemorrhages. Radiology. 2020:202040. https://doi.org/10.1148/radiol.2020202040

55. Utukuri P, Bautista A, Lignelli A, Moonis G (2020) Possible acute disseminated encephalomyelitis related to severe acute respiratory syndrome coronavirus 2 infection. Am J Neuroradiol. https://doi. org/10.3174/ajnr.a6714

56. Parsons T, Banks S, Bae C, Gelber J, Alahmadi H, Tichauer M (2020) COVID-19-associated acute disseminated encephalomyelitis (ADEM). J Neurol. https://doi.org/10.1007/s00415-020-099519

57. Zanin L, Saraceno G, Panciani PP, Renisi G, Signorini L, Migliorati $\mathrm{K}$, Fontanella MM (2020) SARS-CoV-2 can induce brain and spine demyelinating lesions. Acta Neurochir 162(7):1491-1494. https:// doi.org/10.1007/s00701-020-04374-x

58. Palao M, Fernández-Díaz E, Gracia-Gil J, Romero-Sánchez C, Díaz-Maroto I, Segura T (2020) Multiple sclerosis following SARS-CoV-2 infection. Multiple Sclerosis Relat Disord 45: 102377. https://doi.org/10.1016/j.msard.2020.102377

Publisher's note Springer Nature remains neutral with regard to jurisdictional claims in published maps and institutional affiliations. 